\title{
13. PRELIMINARY SEISMIC REFRACTION RESULTS USING A BOREHOLE SEISMOMETER IN DEEP SEA DRILLING PROJECT HOLE 395A ${ }^{1}$
}

\author{
R. S. Jacobson, College of Oceanography, Oregon State University \\ R. Adair and J. Orcutt, Geological Research Division, Scripps Institution of Oceanography²
}

\begin{abstract}
Three seismic refraction lines shot to the Marine Seismic System, a vertical-component borehole seismometer in DSDP Hole 395A at $609 \mathrm{~m}$ sub-bottom depth, have been analyzed. Despite inconsistencies between various velocity determinations in the upper crust, the velocity of the uppermost $600 \mathrm{~m}$ appears to be high, about $4.5 \mathrm{~km} / \mathrm{s}$. Between $600 \mathrm{~m}$ and $1.8 \mathrm{~km}$ sub-bottom, the crust yields an apparent velocity of $4.6 \mathrm{~km} / \mathrm{s}$. This value is somewhat lower than that determined near the base of the hole using acoustic logging tools $(5.0-5.5 \mathrm{~km} / \mathrm{s})$, and is also lower than the average velocity of core samples from the same depth $(5.7 \mathrm{~km} / \mathrm{s})$. The lower crust is unusually thin, only 1.8 to $2.4 \mathrm{~km}$ thick, and has compressional-wave velocities of 6.8 to $7.3 \mathrm{~km} / \mathrm{s}$. Mantle velocities range from 7.8 to $8.2 \mathrm{~km} / \mathrm{s}$. There is little or no velocity gradient in the uppermost kilometers of the crust, but our results indicate widespread lateral inhomogeneities, supporting the observations based on refraction profiles shot for the original site survey.
\end{abstract}

\section{INTRODUCTION}

For the past 30 years, seismic refraction results have described in general terms the oceanic crustal velocity structure, its variation with age, and its relation to the spreading rate at the time of formation (Raitt, 1963; Shor et al., 1971; Bibee and Shor, 1976; Spudich and Orcutt, 1980a). Until a few years ago, correlation of compressional-wave velocities with lithology has been determined primarily on the basis of measurements on rocks dredged from the sea floor (e.g., Christensen and Salisbury, 1975). Velocity measurements on dredge samples show a systematic bias toward higher velocities than may be expected on the basis of seismic refraction velocities. Since seismic refraction techniques are wavelengthlimited $(\sim 200 \mathrm{~m})$, they must also average such features as large-scale fractures, voids, vugs, and joints, all of which profoundly affect the porosity and velocity of the rock. Further, many different lithologies can be averaged together, making correlation of refraction velocities with lithology even more difficult.

With the advent of deep drilling into igneous ocean crust, it may be possible to resolve and quantify the differences between velocity determinations made by seismic refraction, laboratory studies on dredge or core samples, and downhole acoustic logs. A large portion of these differences must be related to the scale of measurement and the wavelengths over which velocity determinations are made, varying from less than a meter to many hundreds of meters (Salisbury et al., 1979). Important questions need to be addressed and answered. Under what conditions do laboratory and log velocities converge? Can seismic refraction velocities be predicted from acoustic logs? Is there a smooth velocity increase

\footnotetext{
${ }^{1}$ Hyndman, R. D., Salisbury, M. H., et al., Init. Repts. DSDP, 78B: Washington (U.S. Govt. Printing Office).

2 Present addresses: (Jacobson) College of Oceanography, Oregon State Univ., Corvallis, OR 97331; (Adair and Orcutt) Geological Research Div., A-015, Scripps Institution of Oceanography, La Jolla, CA 92093.
}

with depth in the uppermost crust, and if so, is it controlled by porosity changes or lithologic changes, or both?

There exist significant difficulties in measuring the velocity structure in the uppermost $500 \mathrm{~m}$ of ocean crust by seismic refraction methods (White and Matthews, 1980; Ewing and Purdy, 1982). These difficulties arise because of the geometry of the experiment, usually involving near-surface explosive charges as sources and either near-surface hydrophones or ocean-bottom seismometers as receivers. The thick water layer acts to mask refracted waves, which penetrate only through the uppermost crust, making identification of arrivals tenuous at best.

One possible way of improving the resolution of upper crustal velocity structure is to use a borehole seismometer as a receiver. The effective use of a borehole seismometer in seismic refraction studies has been demonstrated at DSDP Site 417 (Stephen, 1979; Stephen et al., 1980). Another borehole seismometer has been deployed in DSDP Holes $482 \mathrm{C}$ and 494A, but the results are not yet published. More recently, the Defense Advanced Research Projects Agency (DARPA) and the Naval Ocean Research and Development Activity (NORDA) cosponsored the development of a borehole seismometer called the Marine Seismic System (MSS). The long-range objective of this system is to monitor man-made and natural seismicity over long periods of time. Before Leg 78B, the system was untested in a borehole situation, and a series of engineering tests was needed to ensure operational capability. The Deep Sea Drilling Project had planned to re-enter Hole 395A (Fig. 1), in the central Atlantic, to measure geophysical properties-using downhole logging instruments-to a sub-bottom depth of $600 \mathrm{~m}$ in the igneous crust. Hole $395 \mathrm{~A}$ was selected as an optimal location for testing the MSS, combining downhole geophysical logging with a series of seismic refraction profiles in a coherent geophysical investigation. This experiment would provide a 
unique opportunity to answer some of the questions we have raised here.

DSDP Hole 395A was re-entered in March and April of 1981 . This hole, at $22^{\circ} 45^{\prime} \mathrm{N}, 46^{\circ} 05^{\prime} \mathrm{W}$, is near the Mid-Atlantic Ridge in 7.2-Ma-old crust formed at a half-spreading rate of $1.7 \mathrm{~cm} / \mathrm{y}$. (Hussong et al., 1979). Hussong et al. (1979) observed in their site survey of the area that the geology appears to be very complex. Their seismic refraction results show a diverse range of crustal structure and varying thicknesses and seismic velocities. It was hoped that these results could be improved upon by using the borehole seismometer (BHS) of the Marine Seismic System.

Since it was planned to monitor the BHS in real time aboard the Challenger, it was necessary to have an additional ship, the USNS Lynch, deploy the explosive charges. In addition, the Lynch deployed four University of Texas ocean-bottom seismometers (OBS's) around Hole 395A. Comparison of the OBS and borehole seismometer data would determine whether burial would reduce absolute noise levels, thus increasing the signalto-noise ratio, and whether there are any advantages in using a sub-bottom instrument in inversion techniques and velocity determinations. Unfortunately, none of the data collected by the ocean-bottom seismometers was usable for travel-time inversion, owing to mechanical and electrical failures. A noise comparison between one of the OBS's and the MSS (Adair et al., this volume) demonstrated, however, that the ambient noise was lower at the bottom of the hole by almost two orders of magnitude.

This paper presents the velocity structure determined around Hole 395A using a variety of simple travel-time inversion techniques. We will compare the results presented here with those obtained from the original site survey using OBS's and sonobuoys (Hussong, et al., 1979), and with other regional surveys, core samples, and the acoustic log.

\section{FIELD OPERATIONS}

Four seismic refraction lines were shot to the borehole seismometer (Fig. 1). These lines were originally planned on the basis of previously published bathymetry (Hussong et al., 1979, their figure 3) to reduce the effects of topography. Topographic corrections to the refraction data were expected to be on the order of $0.5 \mathrm{~s}$.

A shot calibration profile was performed to determine the shot size necessary to overcome ambient background noise. This was accomplished by monitoring the BHS in real time aboard the Challenger and relaying the results back to the shooting party aboard the Lynch. The real-time monitoring also made possible adjustment of charge sizes during the refraction profiles themselves.

Information necessary for reducing the refraction data was collected by the Lynch personnel. This information included shot detonation times as recorded by a shot-break streamer, time checks to WWV (a universal time code), depth under the shot, charge size, fuse length, sinking time, and the position, speed, and heading of the Lynch. Clock calibrations were also performed aboard the Challenger.
The topography under the four seismic lines was sufficiently rough to strain the assumptions made in using most travel-time inversion methods. A few sediment ponds were encountered, the thickest pond (apparently) being at Site 395 . The seismic reflection system aboard the Lynch was inoperative, making sediment thickness corrections impossible.

The borehole seismometer data proved to be of exceptionally high quality. Background noise levels were comparable to the quietest OBS sites yet observed, and seismic signal-to-noise ratios were very high (Adair et al., this volume). A total of 112 shots were recorded at a sampling rate of 75 samples/second at six different gain settings. One shot, number 23 , was located directly over the borehole, and will be used to calculate an interval velocity from the seabed to the instrument at $609 \mathrm{~m}$ subbottom.

\section{DATA PROCESSING}

Data recorded by the BHS instrument were digitized downhole at 75 samples/second and sent to the Challenger via a cable, where they were recorded on digital tape. Real-time playback was performed in order to ensure system operation. The raw data have been transcribed into ROSE format (Latraille et al., 1982) by Teledyne Geotech, but not without some problems. Pseudo-random timing errors on the order of $0.5 \mathrm{~s}$ were observed when comparing the transcribed digital data with the real-time playback recordings. A systematic process of comparing times of numerous peaks and troughs from both data sets has reconciled the timing inaccuracy to less than $0.05 \mathrm{~s}$.

Shot detonation times were adjusted for distance offset to the shot-break streamer, and corrected to WWV, as were the borehole data. Shot depths were then corrected to the sea surface and shot-receiver ranges were computed on the basis of Lynch navigation. Topographic corrections were applied to a flat datum, defined by the depth of the seafloor at Hole 395A. The depth used for the topographic correction was measured at the point the waves entered the seafloor, although allowance was made for picking a nearby strong reflector on the echo-sounder recording as the probable location for the signal to enter the seafloor. The topographic correction was designed to replace igneous crust of velocity $6.8 \mathrm{~km} / \mathrm{s}$ above the datum level with water of velocity $1.5 \mathrm{~km} / \mathrm{s}$. It is thus assumed that the upper crust is of constant thickness, and that all topography is the result of undulations in the top of Layer 3. Topographic corrections were as much as $0.82 \mathrm{~s}$. The use of dipping-bottom datum planes could reduce this amount considerably, but would have made it difficult to compare profiles. Finally, the data were filtered from 2 to $20 \mathrm{~Hz}$, using a fourth-order Chebyshev filter, and plotted in reduced record sections.

Seven record sections have been prepared for travel-time analysis. For each of the three lines (Line 3 has not been corrected for timing discrepancies, and will not be discussed further), a true amplitude plot and an autoscaled plot have been prepared. For the true amplitude plot, signal levels have been adjusted for shot size and range, according to the formula

$$
\mathrm{A}=\mathrm{A}_{0}\left(R / R_{0}\right)^{R \exp }\left(W_{0} / W\right)^{W \exp }
$$

where $A$ is the true amplitude, $A_{0}$ is the measured amplitude, $R$ and $W$ are the shot range and weight, $R_{0}$ and $W_{0}$ are reference ranges and weights, and Rexp and Wexp are empirical constants equal to 1.75 and 0.65 , respectively. A seventh record section, from range zero to $10 \mathrm{~km}$, depicts the autoscaled combined short-range refracted arrivals from Lines 1, 2, and 4.

The autoscaled plots are of channel L1, which had sufficiently high gain to show clearly the first refracted arrivals. Unfortunately, the high gain on this channel clipped the later-arriving high-amplitude arrivals. Channel $\mathrm{L} 2$, with a gain about 0.02 that of channel $\mathrm{L} 1$, was used to produce the true amplitude plots. No clipping of signals is evident, but at large ranges, the amplitude only barely exceeded the system noise level. The autoscaled and the true amplitude plots for refraction lines 1, 2, and 4 are shown in Figures 2, 3, and 4, respectively. The autoscaled record section of the combined short-range shots is shown in Figure 5. 


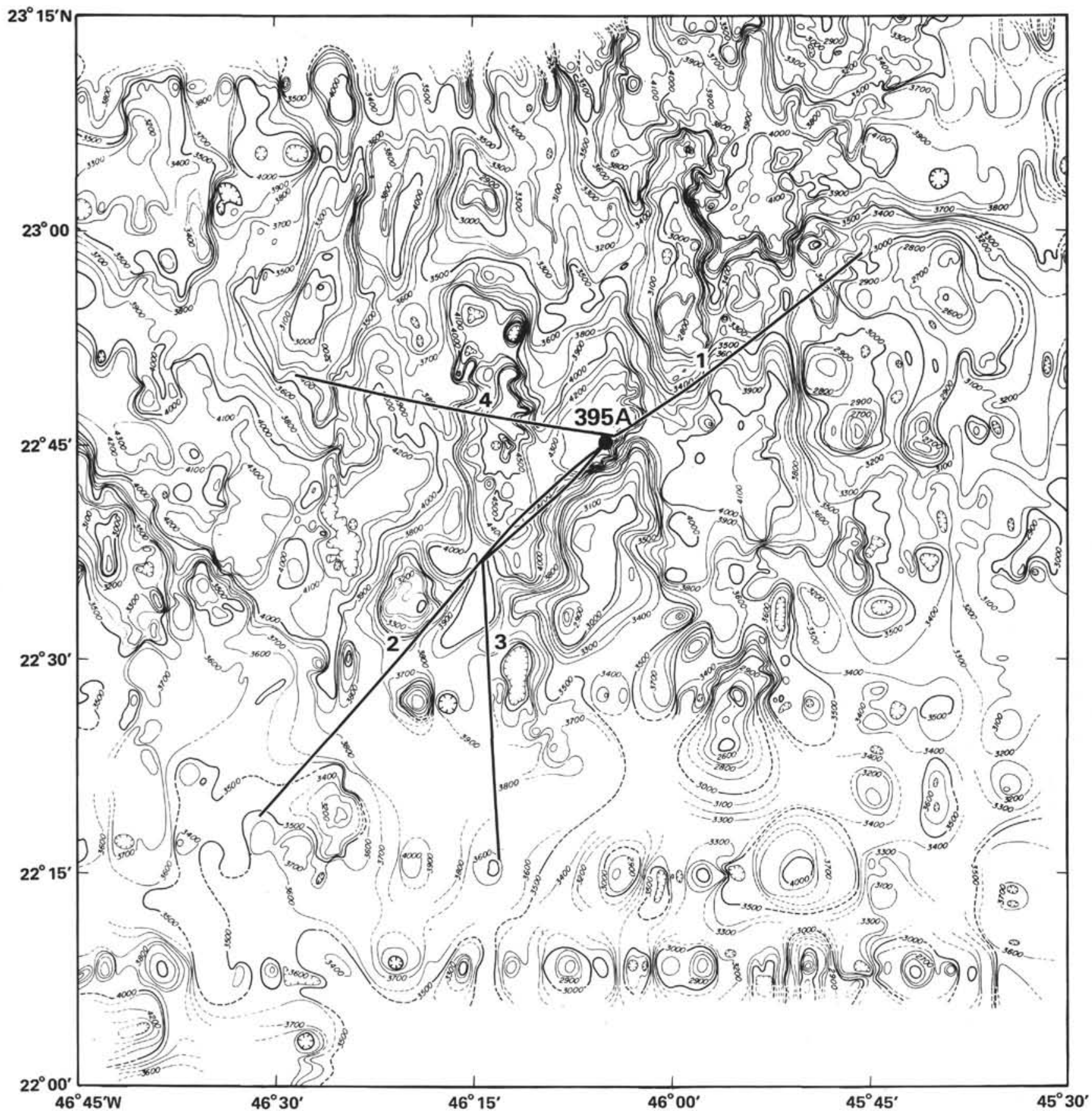

Figure 1. Bathymetric chart of the area surrounding DSDP Hole 395A (reprinted from Hussong et al., 1979), showing the locations of the seismic refraction profiles shot to the borehole seismometer. Depths shown in corrected meters.

The most prominent arrivals are the secondary arrivals, seen in the true-amplitude record sections. These arrivals are interpreted as vertically polarized converted shear waves. The coherence of the arrival times of these waves in the record sections is seriously degraded, since the topographic corrections were made assuming a high refraction velocity to correct the compressional-wave arrivals. The velocities of the shear-wave arrivals vary between 2.5 and $4.7 \mathrm{~km} / \mathrm{s}$.

The first refracted arrivals show a change of polarity at a range of $2.8 \mathrm{~km}$ (Fig. 5), corresponding to a change in propagation direction of the seismic energy at the instrument from above to just below the horizontal. The phase velocity of the seismic energy just beyond this range yields the seismic velocity (at low frequencies) at the depth of the instrument, since the seismic waves have just reached horizontal propa- gation. This will be discussed later in more detail. The first arrivals at all ranges show clear onset times, as recorded on channel L1.

\section{TRAVEL-TIME ANALYSIS}

The first attempt to analyze travel times was to visually fit straight-line segments to the first arrivals of the travel-time curve. This approach yields the classical plane-layer solution of Officer (1958) and Ewing (1963). Each record section has three distinct travel-time branches, corresponding to the classical Layer 2, Layer 3, and mantle arrivals. Breaks in the travel-time curve were de- 


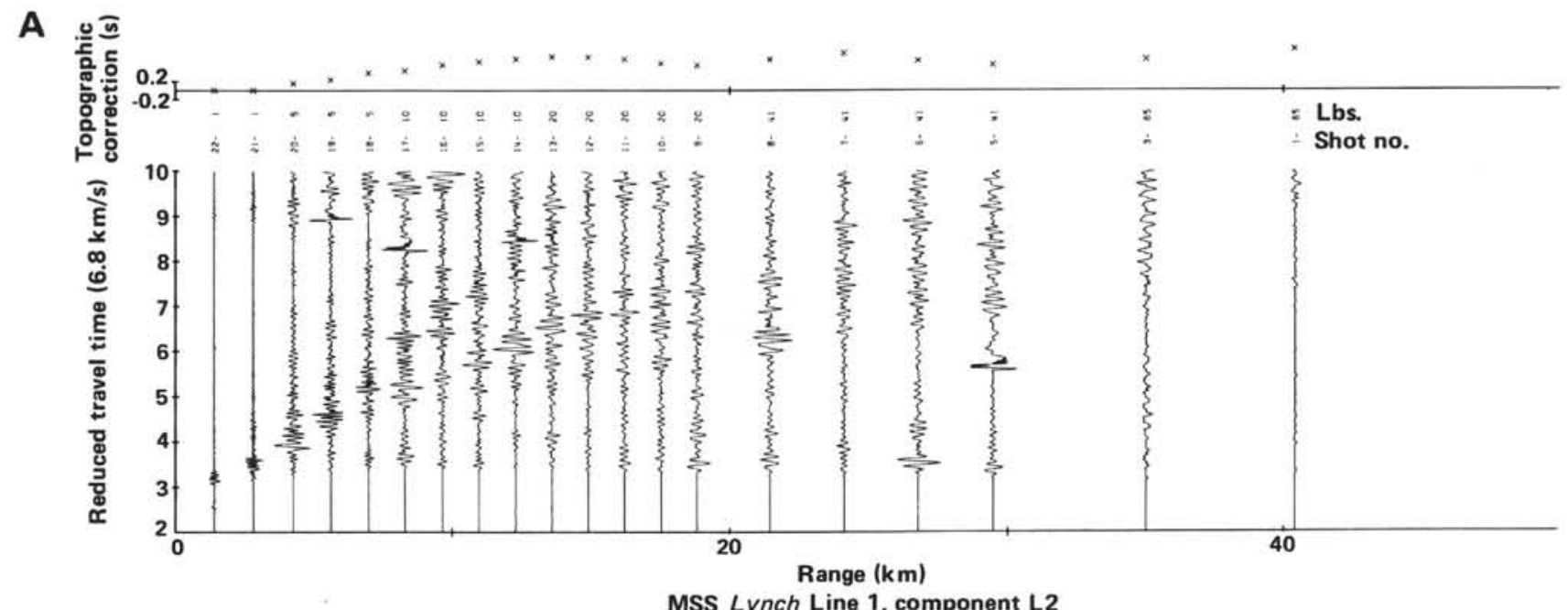

MSS Lynch Line 1, component L2

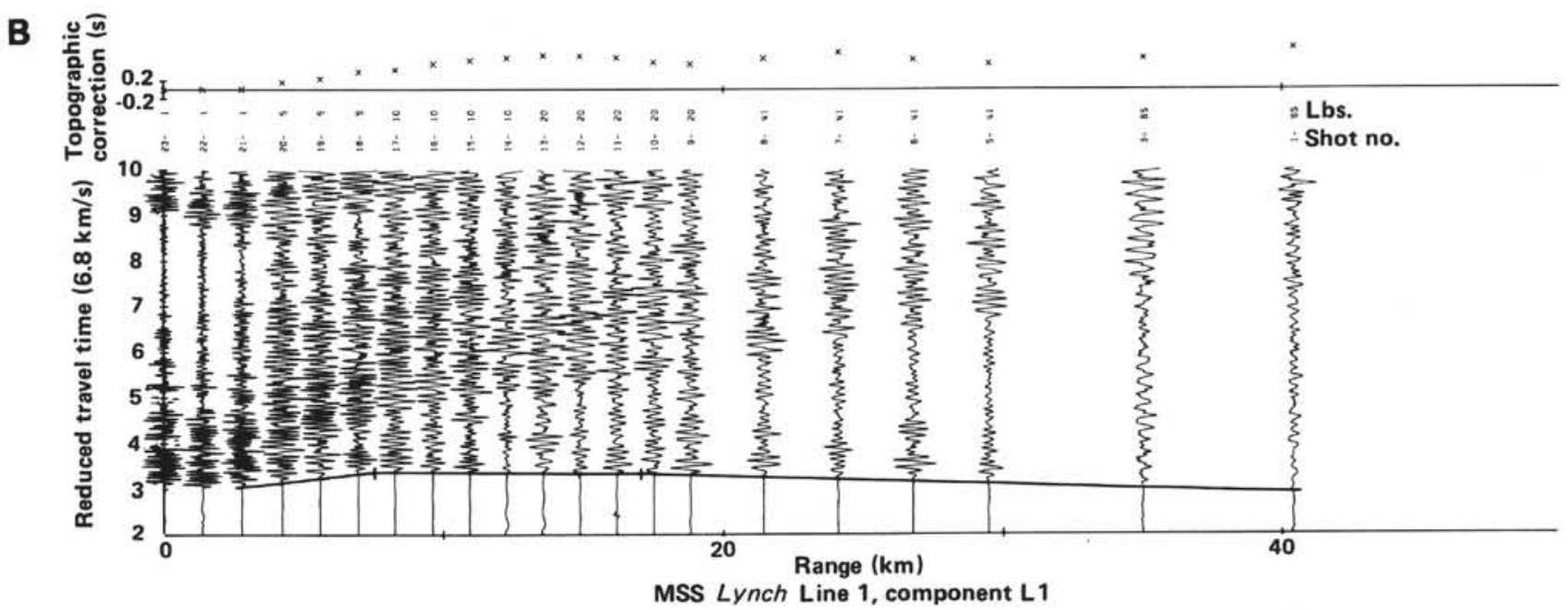

Figure 2. True amplitude (A) and autoscaled (B) record sections for Line 1, located in Figure 1. Both plots are reduced using a velocity of $6.8 \mathrm{~km} / \mathrm{s}$. The true amplitude plot, using component L2, has a weighting applied to each trace to adjust for charge size and receiver-source offset. The autoscaled plot, using component L1, has clipped signal levels beyond the first refracted arrival. Also shown are the straight-line segments used for the velocity analysis.

termined by slope changes and verified by amplitude increases corresponding to critical reflections. The increase of amplitudes in the range of 15 to $25 \mathrm{~km}$ corresponds to the critical reflections of the mantle. The location and character of the critical reflections differed among the record sections, reflecting lateral inhomogeneity in the crust surrounding Site 395.

Plane-layer solutions were calculated for each of the three available lines, assuming flat layers. The uppermost crustal structure was combined for all three profiles. The record section in Figure 5, combining all refracted arrivals available out to $10 \mathrm{~km}$ within the sediment pond, yields an apparent velocity of $4.62 \mathrm{~km} / \mathrm{s}$. Because of the geometry of the receiver and source locations, the polarity of the arrivals detected by the vertical-component seismometer is negative at near zero ranges, changing to positive just when the waves start to refract upward from the horizontal. The polarity change of the first arrivals serves to separate the "oblique refraction branch" of the travel-time curve from the standard head-wave refracted branch, the break occurring at an offset of $2.8 \mathrm{~km}$. The refraction velocity of $4.62 \mathrm{~km} /$ $\mathrm{s}$ observed at the offset range of 3 to $10 \mathrm{~km}$ is inferred to be the average seismic velocity at the depth of the seismometer ( $609 \mathrm{~m}$ sub-bottom). No curvature of the travel-time branch just beyond the range of $3 \mathrm{~km}$ is readily apparent, indicating that upper crustal velocity gradients below $600 \mathrm{~m}$ are extremely low.

Before proceeding to a discussion of the deeper velocity structure, we must first describe the velocity structure in the uppermost $609 \mathrm{~m}$. Shot 23, located directly above the borehole, enables us to determine an average interval velocity to the instrument. Our best determination of this interval velocity is $5.30 \mathrm{~km} / \mathrm{s}$. The velocity of $5.30 \mathrm{~km} / \mathrm{s}$ averages $93 \mathrm{~m}$ of sediment and $516 \mathrm{~m}$ of igneous crust, implying that the uppermost crust has an even higher velocity. The value of the average interval velocity is inconsistent with the inferred velocity at $609 \mathrm{~m}$ depth of $4.62 \mathrm{~km} / \mathrm{s}$. The velocity inconsistency is probably caused by measurement error or lateral refraction of shot 23 into the surrounding hill of igneous crust near the borehole, bypassing the sedimen- 
A

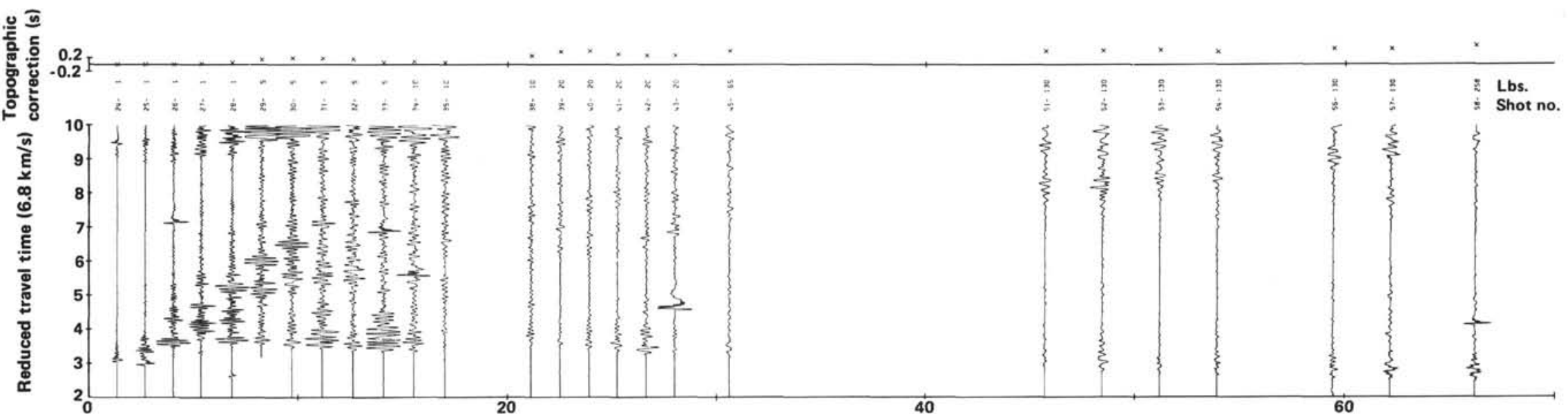

MSS Lynch Line 2, component L2

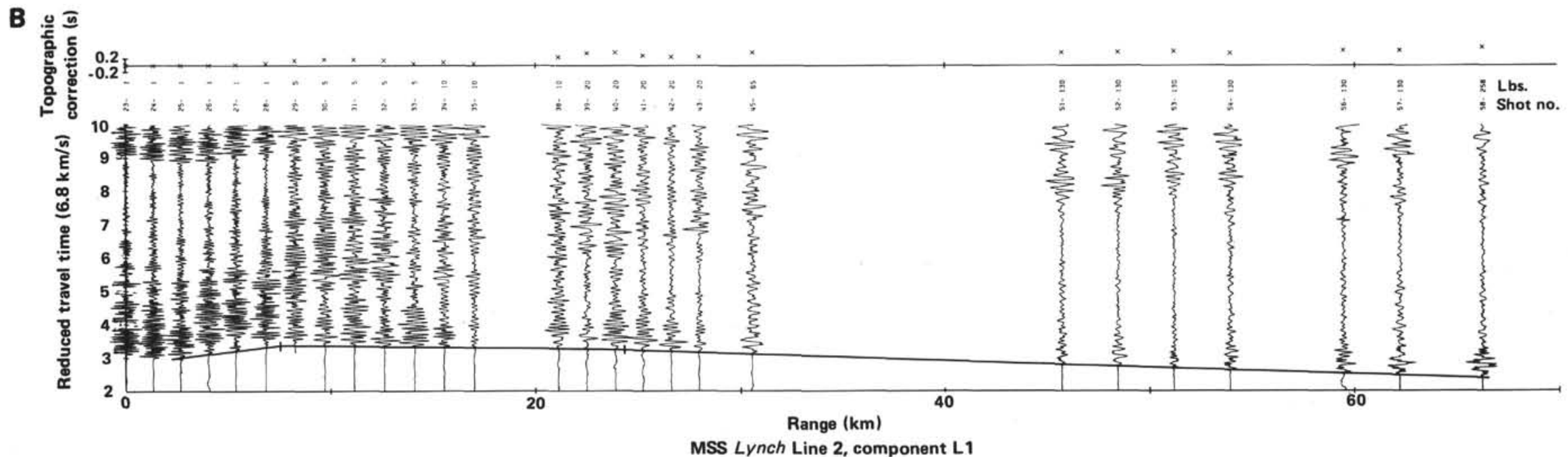

Figure 3. True amplitude (A) and autoscaled (B) record sections for Line 2. 

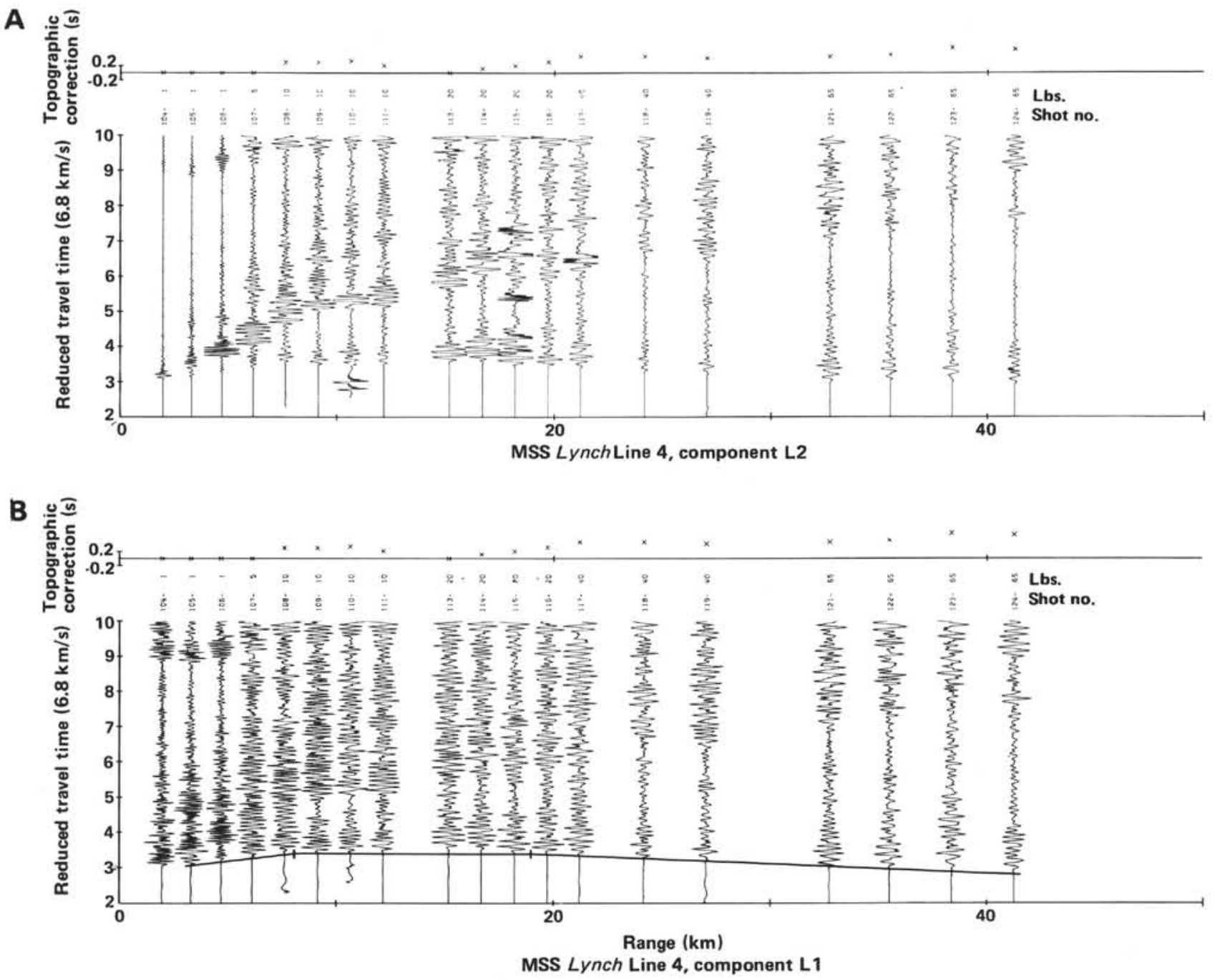

Figure 4. True amplitude (A) and autoscaled (B) record sections for Line 4.

tary layer. Further, our apparent velocity of $4.62 \mathrm{~km} / \mathrm{s}$ may be low, since the sediment thickness increases away from Hole 395A along our shot lines. If we could correct for the sediment thickness along the shot lines, the apparent velocity at short ranges would be close to $5.0 \mathrm{~km} / \mathrm{s}$. That the compressional-wave velocity in the uppermost crust is quite high is indicated by the observed high amplitude of the converted shear-wave arrivals seen in Figures 2, 3, and 4. Spudich and Orcutt (1980b) have noted that $P$ - to $S$-wave conversion is efficient across boundaries with a high velocity contrast, that is, when the uppermost crust displays a high compressional-wave velocity. They also infer that the shearwave amplitude should decrease as the apparent velocity of the shear waves approaches the compressional-wave velocity at the top of the basement. A $P$-wave velocity of around $5.0 \mathrm{~km} / \mathrm{s}$ near the seafloor, shear-wave velocities of 2.7 to $4.7 \mathrm{~km} / \mathrm{s}$, and the observed high amplitudes, are consistent with this hypothesis.

We still need to determine an appropriate velocity for the upper-most crust around Site 395 . The shallow crustal structure at Hole 395A includes $93 \mathrm{~m}$ of sediment. Elsewhere in the sediment pond, the sediment thickness- es can exceed $0.3 \mathrm{~s}$ (Hussong et al., 1979). Outside the pond, little sediment cover was observed, suggesting that lateral inhomogeneity should be taken into consideration. We need to determine a refraction velocity for the upper crust outside the pond, such that the delay time to the $4.62-\mathrm{km} / \mathrm{s}$ layer is satisfied. Knowing the thickness of this layer $(609 \mathrm{~m})$, a velocity of $4.47 \mathrm{~km} / \mathrm{s}$ was calculated. Figure 6 depicts the upper crustal structure used for the modified plane-layer solution.

The velocity structure inferred below the level of the seismometer differs between the three profiles, as outlined in Table 1. The thickness of Layer 2, of velocity $4.62 \mathrm{~km} / \mathrm{s}$, was rather uniform, varying between 1.14 and $1.25 \mathrm{~km}$. Layer 3 velocities vary significantly, from 6.81 to $7.32 \mathrm{~km} / \mathrm{s}$, as did thicknesses, from 1.92 to 2.39 $\mathrm{km}$. Total crustal thickness ranged from 3.67 to 4.25 $\mathrm{km}$. Mantle velocities also showed a wide range of values, between 7.75 and $8.18 \mathrm{~km} / \mathrm{s}$, with $V_{p}$ fast parallel to the spreading direction.

Much of the velocity variation could be the result of dipping layers. We applied the data to a dipping-layer model, solving for the dip and strike of plane layers. The solution indicated that the dips were severe enough 


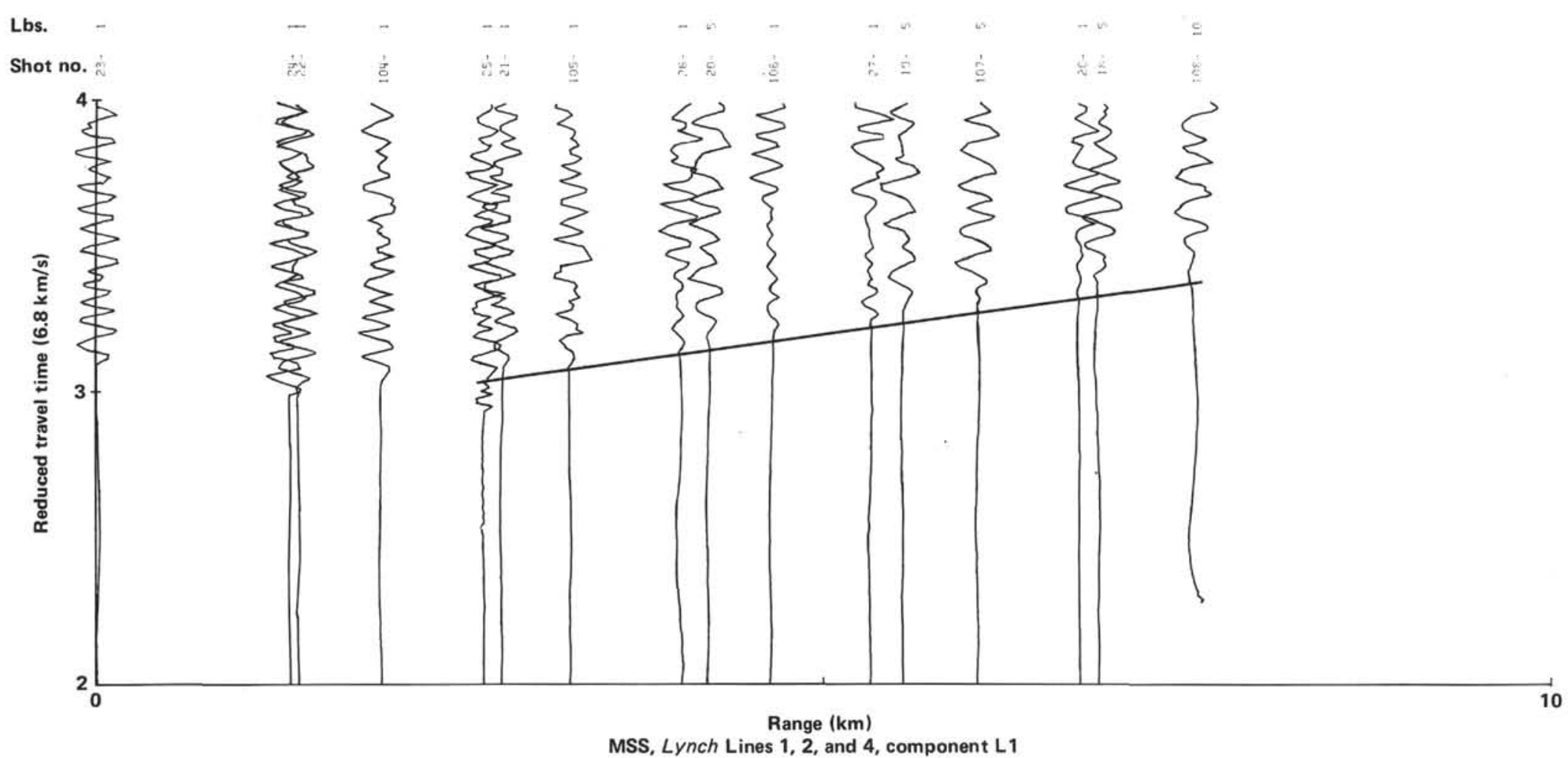

Figure 5. Combined autoscaled record section for all shots from Lines 1, 2, and 4 with an offset of less than $10 \mathrm{~km}$. 


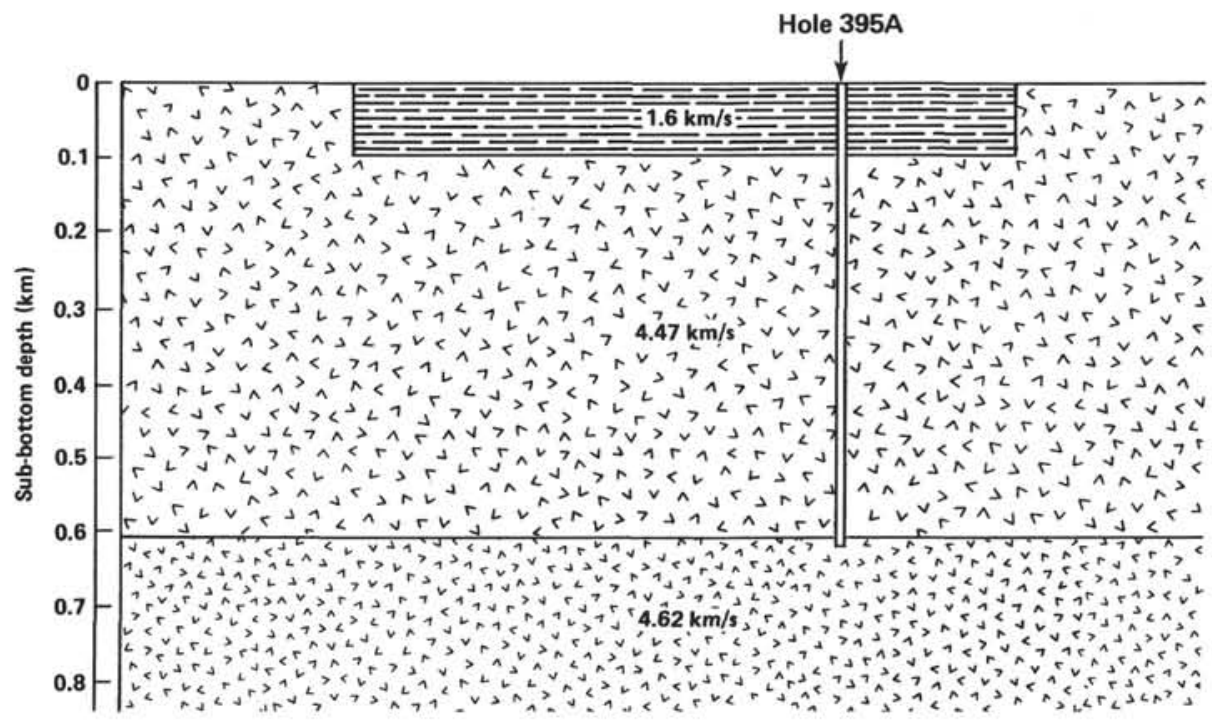

Figure 6. Model of upper crustal velocity structure immediately surrounding DSDP Hole 395A, as deduced from the seismic refraction data. Velocities not corrected for dip.

Table 1. Plane-layer regional solution assuming flat datums.

\begin{tabular}{|c|c|c|c|c|c|c|c|c|c|}
\hline \multirow[b]{2}{*}{ Layer } & \multicolumn{3}{|c|}{ Line 1} & \multicolumn{3}{|c|}{ Line 2} & \multicolumn{3}{|c|}{ Line 4} \\
\hline & $\begin{array}{c}V_{p} \\
(\mathrm{~km} / \mathrm{s})\end{array}$ & $\begin{array}{l}\text { Thickness } \\
(\mathbf{k m})\end{array}$ & $\begin{array}{c}\text { Total } \\
\text { thickness } \\
(\mathrm{km})\end{array}$ & $\begin{array}{c}V_{p} \\
(\mathrm{~km} / \mathrm{s})\end{array}$ & $\begin{array}{l}\text { Thickness } \\
(\mathrm{km})\end{array}$ & $\begin{array}{c}\text { Total } \\
\text { thickness } \\
(\mathrm{km})\end{array}$ & $\begin{array}{c}V_{p} \\
(\mathrm{~km} / \mathrm{s})\end{array}$ & $\begin{array}{l}\text { Thickness } \\
(\mathbf{k m})\end{array}$ & $\begin{array}{l}\text { Total } \\
\text { thickness } \\
(\mathbf{k m})\end{array}$ \\
\hline 0 & 1.509 & 4.4 & & 1.509 & 4.4 & & 1.509 & 4.483 & \\
\hline 1 & $4.47^{\mathrm{a}}$ & 0.609 & 0.609 & $4.47^{\mathrm{a}}$ & 0.609 & 0.609 & $4.47^{\mathrm{a}}$ & 0.609 & 0.609 \\
\hline 2 & 4.62 & 1.140 & 1.749 & 4.62 & 1.247 & 1.858 & 4.62 & 1.178 & 1.787 \\
\hline 3 & 7.04 & 1.921 & 3.670 & 7.32 & 2.393 & 4.251 & 6.81 & 2.368 & 4.155 \\
\hline 4 & 7.75 & & & 7.81 & & & 8.18 & & \\
\hline
\end{tabular}

Note: Drilling results indicate that the uppermost $0.093 \mathrm{~km}$ consists of $1.6 \mathrm{~km} / \mathrm{s}$ sediment.

a Assumed velocity.

that the refracting plane layers crossed each other, a physically unrealizable model. A more complex geometry for the refracting horizons would produce an even more unstable solution. However, a somewhat satisfactory model with flat, non-dipping layers is proposed, having velocities of 4.47 (assumed), 4.62 , and $7.11 \mathrm{~km} /$ $\mathrm{s}$, and a mantle velocity of $7.89 \mathrm{~km} / \mathrm{s}$, and thicknesses of $0.609,1.24$, and $1.85 \mathrm{~km}$, respectively, for the three uppermost layers. Systematic residuals in travel times were evident for all layers, indicating either the presence of dipping layers or lateral variations in velocity.

\section{Comparison with Earlier Refraction Studies}

In the original site survey by Hussong et al. (1979), it was emphasized that the crustal velocity structure exhibited inhomogeneity which reflected the complex geology of the area. Our results certainly support this conclusion. The great variability in Layer 3 and mantle velocities and crustal thicknesses cannot be attributed solely to timing errors. The close-range arrivals, out to $10 \mathrm{~km}$, show fairly good coherence and exhibit unusually wellbehaved travel times (Fig. 5), considering the lack of sediment-thickness corrections. All shots within $10 \mathrm{~km}$ of Hole 395A were within the sediment pond, an obviously downfaulted piece of oceanic crust. The crust under the sediment pond at Site $\mathbf{3 9 5}$ may be laterally homogeneous, but it may also be anomalous when com- pared with the surrounding crust. The sediment pond is deeper than any other seafloor within a radius of 100 $\mathrm{km}$, and also has the thickest sediment cover. The most important evidence of lateral inhomogeneities are the ranges where critical mantle reflections become most prominent. These ranges vary between 15 and $25 \mathrm{~km}$, indicating major structural changes in the crust surrounding Site 395 .

It is instructive to examine the differences between the results of this study and those of Hussong et al. (1979). Figure 7 shows a comparison of our lines with profiles of Hussong et al. having similar geographic placement. Very little agreement exists, either in velocities or crustal thicknesses. The exception is Layer 2: the profiles of Hussong et al. show a range in Layer 2 velocities of 3.9 to $4.8 \mathrm{~km} /$ and a fairly uniform thickness. It appears that Layer 2 is more homogeneous in this area than is the more deep-seated structure.

The results of this experiment, compared with the regional structure given by Hussong et al. (1979), are more encouraging (Fig. 8). The agreement between velocities and lower crustal layer thicknesses are good. Perhaps more surprising is the greater similarity between our three lines than between those of Hussong et al. This must be the result of our only having one seismometer location in an area of lateral complexity, whereas Hussong et al. had more than 10 receivers. 

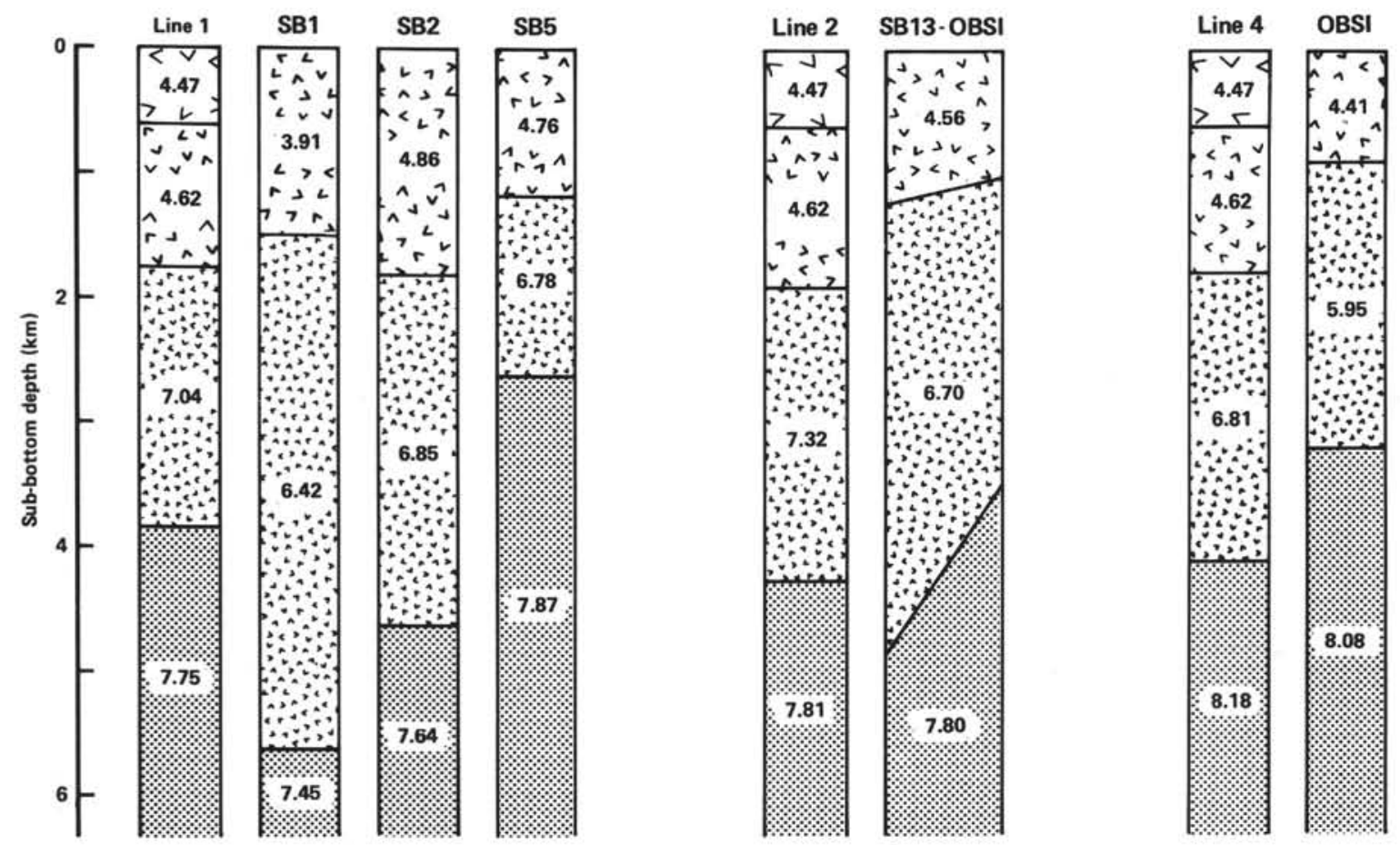

Figure 7. Comparison of crustal velocity structure near Site 395 determined from the DARPA borehole seismometer experiment (Lines 1, 2, and 4) with co-located seismic refraction profiles run by Hussong et al. (1979) using sonobuoys and OBS's. Layer velocities in $\mathrm{km} / \mathrm{s}$.

Other crustal velocity structure determinations have been made reasonably close to Site 395 . Barrett and Purdy (1979) report on the seismic structure at Site 396, situated to the east of the same ridge crest at $23^{\circ} 50^{\prime} \mathrm{N}$, $44^{\circ} 30^{\prime} \mathrm{W}$. This site is on 10-Ma-old crust formed at a half-spreading rate of $1.5 \mathrm{~cm} / \mathrm{y}$. (Purdy, Rabinowitz, and Schouten, 1979). These authors determined a total crustal thickness of $6.8 \mathrm{~km}$, with a 4.6-km-thick Layer 3 (Purdy, Schouten, et al., 1979), shown in Figure 8.

Detrick and Purdy (1980) have reported a series of crustal determinations across the Kane Fracture Zone at $44^{\circ} \mathrm{W}$. The crust south of the fracture zone, created at the same ridge that created the crust at Site 395 , is $7 \mathrm{Ma}$ old, and formed at a half-spreading rate of $1.4 \mathrm{~cm} / \mathrm{y}$. Their results from $\mathrm{OBH} 2$, within $40 \mathrm{~km}$ of the fracture zone, are shown in Figure 8, and more closely resemble ours.

Detrick and Purdy (1980) also mention the possible existence of several small-scale fracture zones south of the Kane Fracture Zone which trend WNW. Hussong et al. (1979) also noted two possible fracture zones trending WNW which offset magnetic anomaly patterns around Site 395. The existence of fracture zones may explain the unusually thin crust under Hole 395A. The well-developed Kane Fracture Zone, just to the north, shows a complete absence of Layer 3 (Detrick and Purdy, 1980).

\section{Comparison with Laboratory and Logging Velocities}

Melson, Rabinowitz, et al. (1979) reported selected laboratory sonic velocity determinations for crustal rocks from Site 395. Their results, for samples from a depth of $609 \mathrm{~m}$ sub-bottom, indicate an average velocity of 5.69 $\mathrm{km} / \mathrm{s}$ for doloritic basalt, greater than our $4.62 \mathrm{~km} / \mathrm{s}$ determination of apparent velocity. It is well known that velocities determined on core samples represent maximum velocities because of a sampling bias toward coherent material. A better indication of in situ velocities may often be obtained by using downhole acoustic logs. The log for Hole 395A (Mathews et al., this volume) recorded reliable velocities only in the deepest part of the hole. The results indicate an interval velocity of $\mathbf{5 . 2 6}$ $\mathrm{km} / \mathrm{s}$. Unfortunately, the acoustic log was unreliable for the shallower structure, and could not be used to verify the lack of velocity gradients deduced above.

\section{SUMMARY}

The preliminary results from three out of four seismic refraction lines shot to the DARPA borehole seismometer implanted in DSDP Hole 395A support the results obtained by Hussong et al. (1979) using oceanbottom seismometers and sonobuoys. Major lateral inhomogeneities are evident in the lower crustal velocity structure, whereas the Layer 2 velocities and thicknesses are more uniform from profile to profile. The gross features of the crust include a 1.85-km-thick Layer 2 overlying a 1.9-km-thick Layer 3 or lower oceanic crust. This crustal section is considerably thinner than that normally expected for Atlantic-type crust. There is little evidence to indicate the existence of velocity gradients within Layer 2, but if gradients do exist, they must be small. Velocity determinations from the sonic logs are considerably higher than the observed refraction velocities, and are somewhat lower than the sonic velocities of discrete samples from the borehole. 

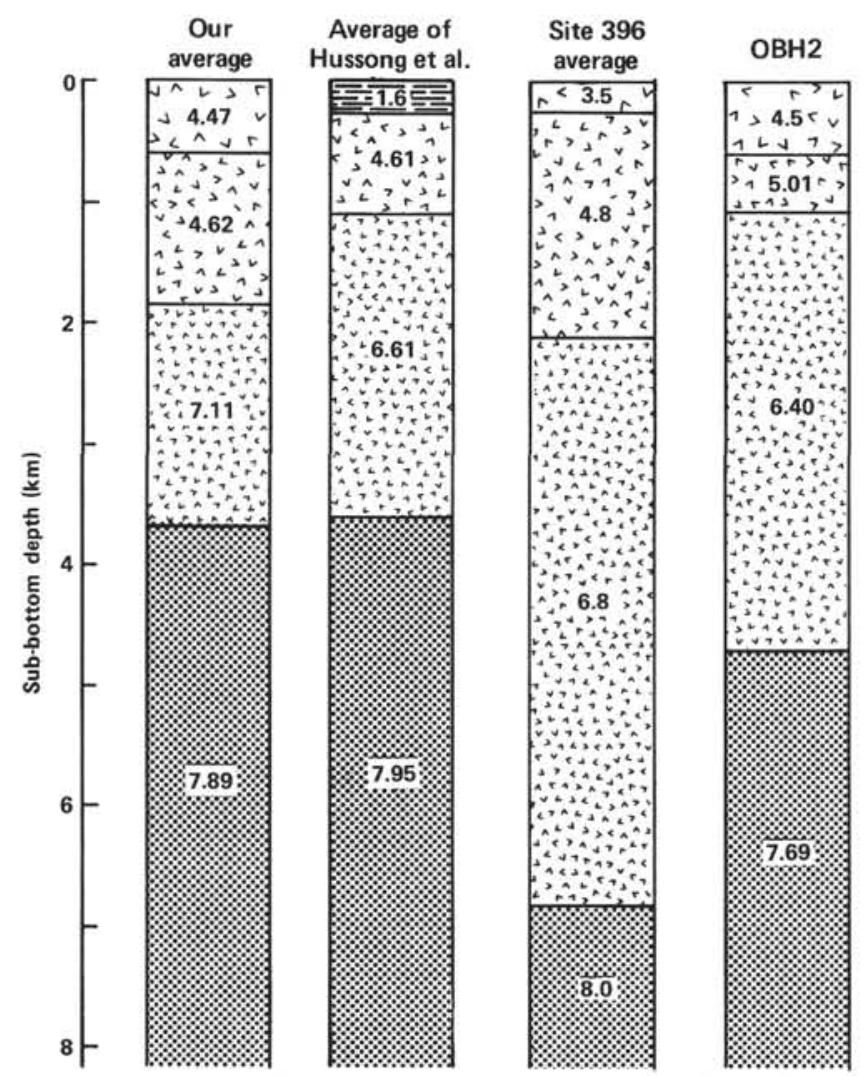

Figure 8. Comparison of the results presented here and the average velocity structure near Site 395 deduced by Hussong et al. (1979). Also shown are the crustal structure near Site 396 (Purdy, Schouten, et al., 1979) and the velocity structure near the Kane Fracture Zone (OBH2), determined by Detrick and Purdy (1980). Layer velocities in $\mathrm{km} / \mathrm{s}$.

The results of the data collected from the borehole seismometer are more self-consistent than those obtained using many OBS's, but this may be the result of having a single sensor in a geologically complicated structure. The use of a borehole seismometer offers considerable advantages in travel-time analysis, especially for determining the velocity at the depth of the sensor. Nonetheless, we expect that the conclusions reached in this chapter will change little with further analysis. Because amplitudes are strongly dependent on vertical and horizontal velocity gradients, the use of synthetic seismograms to refine the compressional- and shearwave velocity structure any further will prove extremely difficult.

\section{ACKNOWLEDGMENTS}

We would like to thank the crew of the USNS Lynch for their cooperation and patience. We especially appreciate the fine effort put forth by the master, E. Maier, without whom many of our results could not have been obtained. We also thank the UT Galveston crew, headed by D. McGowan and P. Donoho, for their efforts in working with the OBS's. We also wish to thank the NORDA Code 360 personnel aboard the Lynch for making the cruise function smoothly. Finally, we with to express our thanks to L. Dorman, F. Duennebier, and M. Salisbury for reviewing this manuscript.

This work was supported by NORDA Code 543, ONR (N0001479-C-0004), the School of Oceanography at Oregon State University, and by a grant from the Defense Advanced Research Projects Agency (F49620-79-C-0019).

\section{REFERENCES}

Barrett, D. L., and Purdy, G. M., 1979. IPOD survey area AT-6: Seismic refraction results. In Melson, W. G., Rabinowitz, P. D., et al., Init. Repts. DSDP, 45: Washington (U.S. Govt. Printing Office), 49-53.

Bibee, L. E., and Shor, B. B., Jr., 1976. Compressional wave anisotropy in the crust and upper mantle of the Pacific. Geophys. Res. Lett., 3:639-642.

Christensen, N. I., and Salisbury, M. H., 1975. Structure and constitution of the lower oceanic crust. Rev. Geophys. Space Phys., 13: 57-86.

Detrick, R. S., Jr., and Purdy, G. M., 1980. The crustal structure of the Kane Fracture Zone from seismic refraction studies. J. Geophys. Res., 85:3759-3777.

Ewing, J. I., 1963. Elementary theory of seismic refraction and reflection measurements. In Hill, M. N. (Ed.), The Sea (Vol. 3): New York (Interscience), pp. 3-19.

Ewing, J. I., and Purdy, G. M., 1982. Upper crustal velocity structure in the ROSE area of the East Pacific Rise. J. Geophys. Res., 87: 8397-8402.

Hussong, D. M., Fryer, P. B., Tuthill, J. D., and Wipperman, L. K., 1979. The geological and geophysical setting near DSDP Site 395, North Atlantic Ocean. In Melson, W. G., Rabinowitz, P. D., et al., Init. Repts. DSDP, 45: Washington (U.S. Govt. Printing Office), 23-37.

LaTraille, S. L., Gettrust, J. F., and Simpson, M. E., 1982. The ROSE seismic data storage and exchange facility. J. Geophys. Res., 87: 8359-8363.

Melson, W. G., Rabinowitz, P. D., et al., 1979. Site $395: 23^{\circ}$ N, MidAtlantic Ridge. In Melson, W. G., Rabinowitz, P. D., et al., Init. Repts. DSDP, 45: Washington (U.S. Govt. Printing Office), 131-264.

Officer, C. B., 1958. Introduction to the Theory of Sound Transmission: New York (McGraw-Hill).

Purdy, G. M., Rabinowitz, P. D., and Schouten, H., 1979. The MidAtlantic Ridge at $23^{\circ} \mathrm{N}$ : Bathymetry and magnetics. In Melson, W. G., Rabinowitz, P. D., et al., Init. Repts. DSDP, 45: Washington (U.S. Govt. Printing Office), 119-128.

Purdy, G. M., Schouten, H., Crowe, J., Barrett, D. L., Falconer, R. K. H., Udintsev, G. B., Marova, N. A., Litvin, V. M., Vlayashko, G. M., Markushevich, V. M., and Zdorovenin, V. V., 1979. IPOD survey area AT-6: A site survey. In Melson, W. G., Rabinowitz, P. D., et al., Init. Repts. DSDP, 45: Washington (U.S. Govt. Printing Office), 39-48.

Raitt, R. W., 1963. The crustal rocks. In Hill, M. N. (Ed.), The Sea (Vol. 3): New York, (Interscience), pp. 85-102.

Salisbury, M. H., Stephen, R., Christensen, N. I., Francheteau, J., Hamano, Y., Hobart, M., and Johnson, D., 1979. The physical state of the upper levels of Cretaceous oceanic crust from the results of logging, laboratory studies and the oblique seismic experiment at DSDP Sites 417 and 418 . In Talwani, M., Harrison, C. G., and Hayes, D. E., (Eds.) Deep Drilling Results in the Atlantic Ocean: Ocean Crust, Am. Geophys. Union, p. 113-134.

Shor, G. G., Jr., Menard, H. W., and Raitt, R. W., 1971. Structure of the Pacific basin. In Maxwell, E. (Ed.), The Sea (Vol. 4): New York (Wiley), pp. 3-27.

Spudich, P., and Orcutt, J., 1980a. A new look at the seismic velocity structure of the oceanic crust. Rev. Geophys. Space Phys., 18: 627-645.

1980b. Petrology and porosity of an oceanic crustal site: results from wave form modeling of seismic refraction data. $J$. Geophys. Res., 85:1409-1433.

Stephen, R. A., 1979. The oblique seismic experiment in oceanic crust-equipment and technique. Mar. Geophys. Res., 4:213-226.

Stephen, R. A., Louden, K. E., and Matthews, D. H., 1980. The oblique seismic experiment on Deep Sea Drilling Project Leg 52. In Donnelly, T. Francheteau, J., Bryan, W., Robinson, P., Flower, M., Salisbury, M., et al., Init. Repts. DSDP, 51, 52, 53, Pt. 1: Washington (U.S. Govt. Printing Office), 675-704.

White, R. S., and Matthews, D. H., 1980. Variations in oceanic upper crustal structure in a small area of the north-eastern Atlantic. Geophys. J. R. Astron. Soc., 61:401-435.

Date of Initial Receipt: January 5, 1983

Date of Acceptance: June 24, 1983 